\title{
Interaction of brain stimulation and conditioned taste aversion: Osmotically induced drinking
}

\author{
PAUL J. KULKOSKY, ANTHONY L. RILEY, STEPHEN C. WOODS \\ University of Washington, Seattle, Washington 98195 \\ and \\ RICHARD KRINSKY \\ University of Southern Colorado, Pueblo, Colorado 81001
}

\begin{abstract}
Water-sated rats received intraventricular injections of hypertonic saline and were given access to a previously poisoned saccharin solution or water on alternate days. Water intake was significantly greater than that of saccharin, which in turn did not differ from water intake following various control procedures. The data are interpreted as extending the finding of Wise and Albin (1973) of disruption of eating induced by electrical stimulation of the lateral hypothalamus by a conditioned taste aversion to the instance of drinking induced by central nervous system (CNS) osmostimulation.
\end{abstract}

Eating elicited by lateral hypothalamic stimulation resembles deprivation-induced eating in its interaction with a number of motivational variables that inhibit or facilitate normal food intake (Sheer, 1961; Valenstein, 1973). Wise and Albin (1973) have recently extended this general conclusion by demonstrating that a conditioned taste aversion established to a previously preferred food temporarily eliminated electrical brain stimulation induced eating of that food. As the aversion extinguished, stimulation-induced eating of the averted food reappeared, but at elevated current thresholds. These findings indicate that the response of eating, when elicited by hypothalamic stimulation, can be effectively inhibited by a previously established conditioned taste aversion. In this regard, therefore, electrical brain-stimulation-induced eating resembles deprivation-induced eating.

The question remains whether other direct manipulations of the central nervous system designed to elicit ingestive behaviors also display these motivational properties. There are a variety of techniques for inducing ingestive behaviors in sated animals (e.g., see Morgane, 1969). Intraventricular injection of hypertonic saline has been frequently employed to induce drinking in the water-sated animal [Andersson (1952, 1953); Andersson \& McCann (1955); Baile, Scott, \& Mayer (1967); Herberg (1962); Mabel, Baile, \& Mayer (1966); Miller $(1957,1961)]$. The drinking induced by this technique has typically been attributed by these researchers to stimulation of periventricular CNS structures responsible for control of osmotic thirst.

This research was supported by National Institute of Health Grant AM-17112 to S. C. Woods and National Science Foundation Grant GB-40314 to R. C. Bolles. The authors thank Denis Mitchell, Ilene Bernstein, and Orville Smith for their helpful suggestions. Requests for reprints should be sent to Paul J. Kulkosky, Department of Psychology NI-25, University of Washington, Seattle, Washington 98195. A. L. Riley is presently at the Department of Psychology, Dalhousie University, Halifax, Nova Scotia, Canada.
In the present experiment, water-sated rats received intraventricular injections of hypertonic saline and were then allowed access to either a previously poisoned saccharin solution or water. The purpose was to ascertain whether drinking elicited by CNS osmotic stimulation could be inhibited by a conditioned taste aversion.

\section{METHOD}

\section{Subjects}

Subjects were seven experimentally naive male Long-Evans rats, approximately 100 days old at the time of surgery. They were housed in individual stainless steel cages and had access to ad-lib Purina Rat Chow and water unless otherwise specified.

\section{Surgery}

Each subject was anesthetized with Halothane and placed in a stereotaxic apparatus. A 4.5-mm 24-ga. Kopf chemical cannula (Model 220) was inserted into the left lateral ventricle and cemented to the skull according to the procedure of Altaffer, DeBalbian Verster, Hall, Long, and D'Encarnacao (1970). The coordinates were: $1.2 \mathrm{~mm}$ posterior to bregma and $1.5 \mathrm{~mm}$ lateral to the mid-saggital suture. Subjects were given 2 weeks to recover prior to the initiation of the experiment.

\section{Procedure}

On Day 1, all subjects were deprived of water but given ad-lib access to food. On the next day, they were given 30-min access to water. This procedure was repeated once a day for 14 days. On Day 15, all subjects received a .1\% sodium saccharin solution for $30 \mathrm{~min}$, followed immediately by an intraperitoneal injection of $20 \mathrm{ml} / \mathrm{kg}$ of a $.15 \mathrm{M} \mathrm{LiCl}$ solution. On Day 16, water was presented at the usual time and continued ad lib thereafter. On the following day, at the time when the rats had formerly received water while deprived, each subject received a 15 -microliter intraventricular injection of $2 \% \mathrm{NaCl}$. For four of the subjects, the water on the home cage was replaced with a $.1 \%$ saccharin solution for $30 \mathrm{~min}$. Water remained on the home cage of the remaining three subjects. After $30 \mathrm{~min}$, intakes were recorded, and the water was replaced on the cages of those rats which had had access to saccharin. Intakes were again recorded $30 \mathrm{~min}$ later; i.e., $60 \mathrm{~min}$ after the injections. On the next day (Day 18), the procedure was repeated except that the rats which had received saccharin on Day 17 drank only water during both 


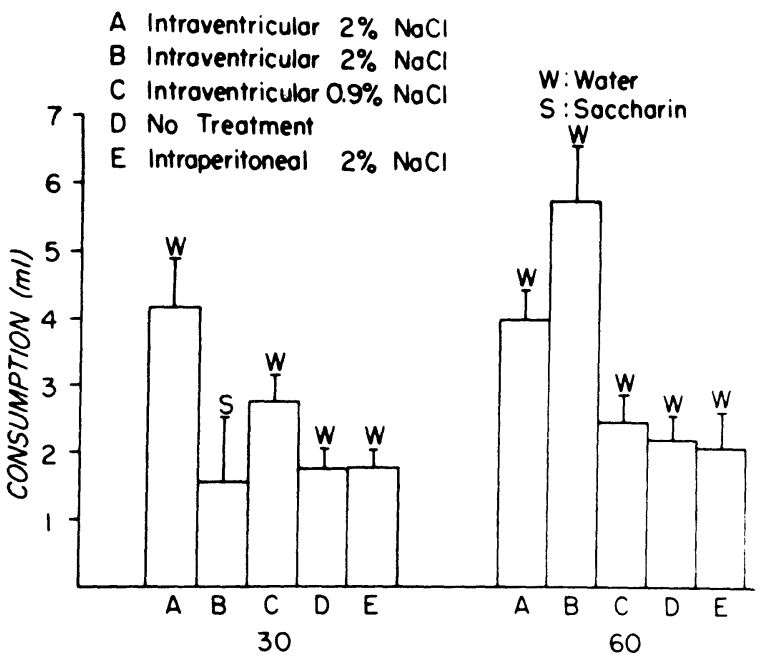

MINUTES AFTER TREATMENT $(\mathrm{t}=2.45, \mathrm{p}<.05)$ intervals, and after no treatment at all at the $30(t=3.05, p<.05)$ and $60-\min (t=4.40$, $\mathrm{p}<.01$ ) intervals.

Water intake at the $60-\mathrm{min}$ interval following the intraventricular administration of $2 \% \mathrm{NaCl}$ when the rats had had only saccharin to drink for the first 30 min after the injections was significantly greater than water intake during the same interval following either intraventricular $.9 \% \mathrm{NaCl}(\mathrm{t}=3.97, \mathrm{p}<.01)$ or intraperitoneal $2 \% \mathrm{NaCl}$ $(\mathrm{t}=5.57, \mathrm{p}<.01)$ or following no treatment at all $(t=6.36, p<.01)$. It was not significantly different from the instance when water had been presented first after intraventricular $2 \% \mathrm{NaCl}(\mathrm{t}=2.13, \mathrm{p}>.05)$. None of the control intakes differed reliably at either interval.

Examination of the brains after injection of cresyl violet stain revealed perfusion of the entire ventricular system from the lateral ventricles through the third ventricle to the cisternum magnum of each subject.

\section{DISCUSSION}

Figure 1. Mean liquid intake (in milliliters) at the 30 and 60-min intervals under the various conditions. Lines above the means represent one standard error of the mean.

30-min intervals following the injections whereas the rats which had not received saccharin on Day 17 received saccharin during the first 30 -min interval and water during the second. It should be reiterated that the water was then continued ad lib after the second 30-min intakes were recorded.

On Day 19, all subjects received a 15-microliter intraventricular injection of isotonic $(.9 \%) \mathrm{NaCl}$, and water intakes were recorded after 30 and $60 \mathrm{~min}$. On Day 20, no treatment was given, and water intakes were taken at the usual $30-$ and 60-min intervals. On Day 21, all subjects received an intraperitoneal injection of 15 microliters of $2 \% \mathrm{NaCl}$, and water intakes were recorded after 30 and $60 \mathrm{~min}$.

At the conclusion of the experiment, all subjects were given intraventricular injections of 15 microliters of cresyl violet stain and were sacrificed with an overdose of sodium pentobarbital. The brains were promptly removed to determine whether the cannulae placements were in the lateral ventricles.

Consumption data were analyzed with correlated t tests.

\section{RESULTS}

Consumption data are summarized in Figure 1. Mean intake of saccharin on Day 15 was $19.6 \mathrm{ml}$ and did not differ significantly from mean water intake $(20.6 \mathrm{ml})$ on Day $14(\mathrm{t}=0.66, \mathrm{p}>.05)$. Because there were no reliable differences between the instance when saccharin was presented on Days 17 and 18, that data has been combined in Figure 1. Water intake $30 \mathrm{~min}$ after the injection of intraventricular $2 \% \mathrm{NaCl}$ was significantly greater than saccharin intake at the same interval $(\mathrm{t}=3.13, \mathrm{p}<.05)$. Water intake after the intraventricular administration of $2 \% \mathrm{NaCl}$ was also significantly greater than water intake in any of the control conditions; i.e., after the intraventricular administration of $.9 \% \mathrm{NaCl}$ at both the $30-\mathrm{min}(\mathrm{t}=3.25$, $\mathrm{p}<.02)$ and the 60-min $(\mathrm{t}=3.36, \mathrm{p}<.02)$ intervals, after the intraperitoneal administration of $2 \% \mathrm{NaCl}$ at both the $30-\mathrm{min}(\mathrm{t}=4.13, \mathrm{p}<.01)$ and the $60-\mathrm{min}$
The data show clearly that a conditioned taste aversion will inhibit fluid intake induced by direct osmotic stimulation of the brain, thus extending the finding of Wise and Albin (1973) to the case of adequate brain stimulation for drinking. When a previously poisoned solution was presented instead of water after osmostimulation, intake did not differ from control intake. Water intake following osmostimulation was approximately double that after the osmolarity control procedure (intraventricular $.9 \% \mathrm{NaCl}$ ), the systemic absorption control procedure (intraperitoneal $2 \% \mathrm{NaCl}$ ) or no treatment at all. Further, water intake in the $30 \mathrm{~min}$ after saccharin had been available in the osmostimulation condition exceeded that of the same interval when water had been presented first, although the difference was not significant. This indicates that although motivationally adequate stimuli for drinking were present, performance was inhibited by the conditioned taste aversion to saccharin, as is the case when the aversion is tested under the conditions of water deprivation (e.g., see Revusky \& Garcia, 1970; Rozin \& Kalat, 1971).

Wise and Albin (1973) speculated that their data constitutes "perhaps the most striking indication that inhibitory influences involving extrahypothalamic mechanisms can overcome the motivational effects of lateral hypothalamic stimulation" (p. 295). They further speculated that these inhibitory influences may comprise descending (i.e., "cortical," p. 295) influences. However, Woods, Lawson, Haddad, Rabe, and Lawson (1974) have recently demonstrated that micrencephalic rats with drastically reduced forebrains can learn taste aversions and their reversals as well as normal rats. This would appear to reduce the potential role of the cerebral cortex as a structure essential to the performance of conditioned taste aversions. 
In summary, the present experiment demonstrates that a conditioned taste aversion can effectively inhibit drinking induced by brain osmostimulation, thus showing that CNS-stimulated drinking can be disrupted by a procedure that also disrupts water-deprived drinking (Revusky \& Garcia, 1970; Rozin \& Kalat, 1971).

\section{REFERENCES}

Altaffer, F. B., De Balbian Verster, F., Hall, S., Long, C. J., and D'Encarnacao, P. A simple and inexpensive cannula technique for chemical stimulation of the brain. Physiology and Behavior, 1970, 5, 119-121.

Andersson, B. Polydipsia caused by intrahypothalamic injections of hypertonic $\mathrm{NaCl}$-solutions. Experientia, 1952, 8, 157-158.

Andersson, B. The effect of injections of hypertonic $\mathrm{NaCl}$-solutions into different parts of the hypothalamus of goats. Acta Physiologica Scandinavica, 1953, 28, 188-201.

Andersson, B., \& McCann, S. M. A further study of polydipsia evoked by hypothalamic stimulation in the goat. Acta Physiologica Scandinavica, 1955, 33, 333-346.

Baile, C. A., Scott, F. A., \& Mayer, J. Eating and drinking induced by cerebral-ventricular injections in rats with lesions in the lateral hypothalamus. Experientia, 1967, 23, 1033-1034.

Herberg, L. J. Physiological drives investigated by means of injections into the cerebral ventricles of the rat. Quarterly Journal of Experimental Psy chology, 1962, 14, 8-14.
Mabel, J. A., Baile, C. A., \& Mayer, J. Hyperphagia induced by ventricular pressure and pentobarbitone in normal and hypothalamic obese rats. Lancet, $1966,2,472-473$.

Miller, N. E. Experiments on motivation: Studies combining psy chological, physiological, and pharmacological techniques. Science, 1957, 126, 1271-1278.

Miller, N. E. Learning and performance motivated by direct stimulation of the brain. In D. E. Sheer (Ed.), Electrical stimulation of the brain. Austin: University of Texas Press, 1961.

Morgane, P. J. (Ed.), Neural regulation of food and water intake. Annals of the New York Academy of Sciences, 1969, 157 . 531-1216.

Revusky, S. H., \& Garcia, J. Learned associations over long delays. In G. H. Bower and J. T. Spence (Eds.), The psychology of learning and motivation: Advances in research and theory. New York: Academic Press, 1970.

Rozin, P., \& Kalat, J. W. Specific hungers and poison avoidance as adaptive specializations of learning. Psychological Review, $1971,78,459-486$.

Sheer, D. E. (Ed.), Electrical stimulation of the brain. Austin: University of Texas Press, 1961.

Valenstein, E. S. (Ed.), Brain stimulation and motivation: research and commentary. Glenview, Ill: Scott, Foresman, 1973.

Wise, R. A., \& Albin, J. Stimulation-induced eating disrupted by a conditioned taste aversion. Behavioral Biology, 1973, 9 , 289-297.

Woods, S. C., Lawson, R., Haddad, R. K., Rabe, A., \& Lawson, W. E. Reversal of conditioned aversions in normal and micrencephalic rats. Journal of Comparative and Physiological Psy chology, 1974, 86, 531-534.

(Received for publication November 25, 1974; revision accepted April 17, 1975.) 